\title{
The Impact of Physical Distancing on the
}

\section{Sharing Economy}

\section{K. A. Karthik ${ }^{1}$ and Manish Sinha ${ }^{2}$}

\begin{abstract}
The purpose of this research is to assess the possible impacts of physical distancing, implemented as a precaution against COVID-19, on businesses that depend on sharing economy, with an emphasis on developing economies. While COVID-19 has already been ravaging economies, there is a need to examine its impact on businesses that thrive on shared resources, which is a relatively new model, and thus merits an impact assessment.
\end{abstract}

The methodology includes extensive background research on the origins of COVID-19, economic impacts of historic pandemics and examining the financial statements over the last six months of business that are purported to be affected, to assess the impact. This in addition to qualitative interviews of users of shared spaces and facilities, and collating media sources for stance taken by firms affected.

The study aims to highlight the need for evolved business models to factor in physical distancing in order to adapt and stay insulated from future threats.

JEL classification: D12, J28, L83, R41

Keywords: COVID-19, shared economy, social distancing, lockdown, co-working, co-living, shared transport

\footnotetext{
${ }^{1}$ SCMHRD, Symbiosis International University, Pune, India. Email address: Karthik_k@scmhrd.edu

${ }^{2}$ SCMHRD, Symbiosis International University, Pune, India. Email address : manish_sinha@scmhrd.edu
} 


\section{INTRODUCTION AND LITERATURE REVIEW}

Pandemics are nothing new in human history. In fact, pandemics act as a stark reminder that man is still at the mercy of nature. Even post-nineteenth century, notwithstanding the exponential advances achieved in medicine, global pandemics have intermittently been ravaging human lives (Spanish Influenza of 1918-19, AIDS, MERS, SARS, etc.). Although there has not been a pattern to the occurrence of pandemics, one response has almost always been even - scapegoating and disowning of successful practices, industries and even empires. To exhibit, here is a chronological list of some of the pandemics and their aftermaths:

i. $541 \mathrm{AD}$ - Originating in Egypt, the Justinian plague spread throughout the Mediterranean, causing massive economic struggle. Carried by fleas and rats, the bubonic plague eventually killed about 50 million people ( $26 \%$ of world's population) over the next couple of centuries. As described in the book Justinian's Flea (Rosen, 2007), it prevented the consolidation of the Roman Empire by emperor Justinian and fostered an atmosphere that spurred the rapid spread of Christianity.

ii. $\quad 1350 \mathrm{AD}$ - The black death, responsible for the death of one-third of the world population, was the second largest outbreak of the bubonic plague and spread rapidly across Europe. Dead bodies lined the streets and remained rotting on the ground. Jews were accused of poisoning food and water sources (Cohn, 2007). As indicated in a paper published by the George Washington University, the black death unleashed a wave of crime, sexual and religious excess and widespread persecutions of Jewish communities (Jedwab, 2017). Between 1348 and 1351, almost the entire European Jewish communities in many areas were eradicated.

iii. $1918 \mathrm{AD}$ - In terms of overall illness and death, the Spanish flu pandemic is among the greatest public health disasters in recorded history (Waring, 1964). It was the result of a highly pathogenic, transmissible strain of influenza that emerged at a time when populations that previously would have had limited contact with one another were brought together by World War I (Hastings, 2016). While previous pandemics travelled mostly along trade routes and communication lines, the spread of the flu was accelerated by the military context in which it developed. Meanwhile, trench warfare in Europe provided ideal conditions - poor sanitation, overcrowding, and limited health services - to facilitate disease transmission (Humphries, 2014). A 2002 estimate puts the toll at around fifty million, with an upper limit as high as a hundred million deaths (Johnson, 2002). It is said that the flu had far reaching consequences on the collective psyche of citizens; in USA the pandemic is an attributed reason for the Great Depression of the 20s (Detrixhe, 2020).

iv. $\quad 1981-A I D S$ started appearing in mainstream society in Florida, USA in 1981. It showed up in areas having concentrations of homosexual populations, and was spread through reused needles and unprotected sex. According to the World Health Organization (WHO) and the Joint United Nations Programme on HIV/AIDS (UNAIDS), AIDS is the fourth leading cause of death worldwide and the leading cause of death in sub-Saharan Africa. According to 1999 estimates, 18.8 million adults and children have died of HIV/AIDS since the beginning of the epidemic ((UNAIDS), 2002); an estimated 34.3 million people 
worldwide were living with HIV/AIDS at the end of 1999, and an estimated 15,000 people became infected each day (Gayle, 2001). The epidemic has already devastated scores of individuals, families and communities, left millions of children orphaned, disrupted village and community life and increasingly contributed to the erosion of civil order and economic growth.

These phenomena provide interesting insights into the behavioural changes displayed by populace in the aftermath of a pandemic. As the world reels under a new wave of pandemic (COVID-19) in the current times, it is prudent to analyse its effects on our society.

\section{Responses to COVID-19 and Their Impact on World Economies}

The novel corona virus SARS-CoV-2 is the seventh coronavirus known to infect humans. (Ren, et al., 2020). It was first identified in late 2019 when a wave of pneumonia swept over Wuhan in Hubei province, China (Zhou, et al., 2020). As of early April, the WHO pegs the damage at $15,21,252$ confirmed $(85,054)$ cases and 92,798 deaths $(7,277)$ worldwide. While conspiracy theories abound with regard to the virus being a possible creation in lab, most of the studies point to a natural origin, including publications by the journal Nature (Andersen \& Rambaut, 2020).

Physical distancing was recommended as the first role of defence against the rapidly spreading pathogen, as can be seen in a paper published in Lancet Public Health (Prem \& et al, 2020). Different countries implemented this strategy in different ways. China aggressively enforced massive lockdowns on whole cities, aided by an authoritarian government and a collectivist culture, as described by a leading Indian daily (TNN, 2020). The United Kingdom, which started with a relatively leisurely approach towards distancing, eventually adopted a more stringent enforcement, following the publishing of a paper by the Imperial College (Ferguson \& Laydon, 2020). In India, in what was termed as a 'timely, comprehensive and robust' response by Dr. Henk Bekedam, WHO representative to India, the whole country was asked to stay at home under 'Janata Curfew'.

Closures, lockdowns and physical distancing also affect the economies of countries. As more people stay indoors, the primary impact is on transportation/automobile sector, followed by blue collar industries like agriculture, manufacturing and construction.

In the foreword of World Economic Outlook of April 2020, the International Monetary Fund (IMF) economic counsellor, Gita Gopinath, stated: 'It is very likely that this year the global economy will experience its worst recession since the Great Depression, surpassing that seen during the global financial crisis a decade ago' (IMF, 2020).

The secretary general of the Organisation for Economic Cooperation and Development (OECD), Angel Gurría, in his statement for the G20 videoconference summit on COVID-19, March 2020, stated: 'Our latest estimates show the lockdown will directly affect sectors amounting to up to one third of GDP in the major economies. We calculate that, for each month of containment, there will be a loss of 2 percentage points in annual GDP growth. The tourism sector alone faces a decrease in output anywhere between $50 \%$ to $70 \%$ in this period. Many economies will fall into recession' (OECD, 2020). 
According to a report by members of the United Nations Industrial Development Organization (UNIDO), developing countries are expected to suffer the most. (Cantore \& Hartwich, 2020). Developing countries are characterised by low and middle income families, a massive informal sector, migrant workers and limited access to quality healthcare. The restrictions imposed, combined with reduced trade and investment could lead to a major chunk of population being rendered jobless.

The latest World Bank's Africa's Pulse report states that several non-resource-intensive countries in the sub-Saharan region depend significantly on tourism for income, export revenues and employment, and will be heavily affected by disruptions to international travel. Simulations show that compared with a no-COVID base case, growth in sub-Saharan Africa could fall by up to 5.2 to 6.3 percentage points. On this basis, real GDP growth in the region is projected to decline up to -3.0 percent in 2020, from 2.4 percent in 2019 (World Bank, 2020, pp. 43-44).

The Economic Commission for Latin America and the Caribbean (ECLAC) estimates a 1.8 per cent contraction in regional gross domestic product (GDP), which could raise unemployment by 10 per cent; those living in extreme poverty could increase from 67.4 to 90 million. Major effects would be through: decrease in the economic activity of several of the main importers regional of goods; fall in the demand for tourism services (esp. Caribbean countries); interruption of global value chains (esp. Mexico and Brazil); fall in the prices of basic commodities (esp. raw material exporting nations) and investors' greater risk aversion amid worsening global financial conditions (ECLAC, 2020).

The Asian Development Bank, in its updated Asian Development Outlook 2020, expects that growth in the continent will go down sharply to 2.2 per cent in 2020, but interestingly, South Asia would face a milder slowdown. Growth in South Asia will decelerate to 4.1 per cent in 2020 and then recover to 6.0 per cent in 2021, largely tracking the trend in the dominant Indian economy. GDP performance would remain strong in countries like Bangladesh and Bhutan, while Maldives and Sri Lanka would suffer (2020).

\section{About the Sharing Economy}

As we saw at the beginning of the paper, every pandemic has had a negative footprint over thriving businesses and has burst many bubbles. With COVID-19, one important bubble that seems to be poised to burst is the sharing economy sector. With strict physical distancing and hygiene advisories in place, it is next to impossible for a person to use many of the modern services such as shared transportation and shared living at travel destinations. Besides, one might also feel reluctant to work at a co-working space. In this light, it's a worthwhile exercise to study the origins of sharing economy, and the conducive factors that helped it thrive.

The basis for a sharing economy is communities that come together, where members share their resources with each other. This is a relatively new economic model, where the focus is not on ownership, but rather on sharing. The model includes sharing of movable and immovable assets, services and other belongings. 
eBay is popularly regarded as the precursor to the sharing economy model. Started in 1995 , the open marketplace allowed people to buy or sell their goods and services $24 / 7$. This new model directly connected sellers with buyers, excluding middlemen from the equation. It fundamentally changed the way people thought about the market. You could sell just about anything - an advertising space on your forehead, a right to name a baby or even a lifestyle (case of Ian Usher). eBay liberated the marketplace.

In a few years, aided by the internet, technology companies cropped up across the globe. They offered platforms for people to exchange their services in all sorts of niches. This also ushered in the 'gig economy' model that allowed people to offer their services as freelancers, right from babysitting or dog walking in their free time, up unto building complex digital infrastructures like mobile applications or websites.

With the ability to harness beneficiaries from around the world and to offer their goods and services at competitive prices, sharing economy models have an edge over traditional retailers. Add to this the ability to offer more variety at lower costs, and the businesses boomed. By getting a foothold in niche markets, businesses grew in size as well. Take, for example, the case of Airbnb or Uber neither of them own their properties or cabs respectively, yet they clock in thousands of transactions per minute globally.

The scope of this paper is to examine the impact on some of these sharing economy firms in India, which fall in the direct line of fire of physical distancing and have been affected by COVID-19. There are three avenues that the researchers intend to explore:

1. How has COVID-19 impacted consumer behaviour in relation to sharing economy?

2. How has the pandemic affected the mindsets of people in the long and short run?

3. How are the interpersonal interactions being redefined in shared spaces?

\section{RESEARCH METHODOLOGY}

The primary question the researchers tried to answer through this research was: 'How has COVID19 and physical distancing impacted consumer behaviour towards sharing economy?' Primary qualitative data was collected by means of interviewing the consumers of shared facilities. The interviews consisted of open ended questions over phone, text and face-to-face interactions; the responses were recorded with their consent, translated (in case of vernacular interactions) and transcribed. These responses were then analysed for underlying patterns that could reveal possible behavioural changes in response to the changing times.

The rationale behind using a qualitative method was the aim to produce contextual real-world knowledge about consumer behaviour. The researchers have taken care not to influence the perceptions or opinions of the interviewees.

Participants mostly fell under the age group of 24-35. This group was chosen for their prolific usage of shared facilities. The interviews were unstructured, and usually lasted around 10 minutes. Interviewees were based in different metropolitan locations in India; they were either primary or secondary contacts of the researchers. 
Karthik \& Sinha | The Impact of Physical Distancing on the Sharing Economy

An allied question for which the researchers tried to find the answer was: 'How is the industry responding to the changing consumer behaviour?' In this case, the researchers collected data through secondary sources such as published media snippets and company statements.

\section{RESULTS}

\section{Shared Living}

The researchers interviewed six people from the following cities: Mumbai, Pune, Bengaluru, Belagavi, Hyderabad and Chennai. The users either lived in shared accommodations full time, or used them on temporary basis (for short stays in different cities) or used them fleetingly (in case of travels). While most respondents subscribed to these living spaces, in one case the interviewee shared his property with guests on a commercial basis. The facilities ranged from paying-guest (PG) accommodation to branded co-living spaces to dormitories and homestays.

The new millennium saw India opening up its economy. And with it came companies vying to establish a foothold in the lucrative Indian market and service sectors. More people flowed into cities from rural parts of India, in the expectation of a steady job. To cater to these companies, which usually hired candidates with a college/university degree, educational institutions mushroomed up across Indian cities, which in turn attracted more students. This dual influx of students and employees into cities spurred a rapid growth of PG facilities. PGs offered food and accommodation to residents for a monthly, yearly or even weekly subscription. However, PGs were unregulated for a long time, with no uniform standards of rent, facility or safety. Often, residents were cramped up - up to three people sharing a room. Over time, competition entered shared living market in the form of branded accommodation firms such as Oyo Rooms, Nestaway and so on, which promised standardized, hygienic, more breathable spaces at affordable prices. In light of physical distancing due to COVID-19, the researchers interviewed users of co-living spaces to find out how they were managing.

In one case, the interviewee had to move out of her current space: 'When I returned to my apartment, the earlier occupant had moved out and a new person was in. I didn't want to stay with unfamiliar people, since there was no way of trusting their travel history. So I shifted to a different apartment where my friend lived.'

The hospitality industry suffered a severe blow during the lockdown months of COVID-19 in India. Since people were restricted from venturing out for leisure, tourism shuddered to a halt and guest accommodations ran dry. In an interview dated 6 June 2020 by Outlook magazine, when asked to quantify the impact of COVID-19 on their revenue, Oyo Rooms' founder Ritesh Agarwal has stated thus: 'OYO much like the industry has also been impacted during this crisis. Our occupancy rates and therefore, revenue has reduced by 50-60 per cent. We are also seeing trends of around 75 per cent drop in occupancies in established hotel chains globally' (Anon., 2020).

One respondent who regularly uses a branded co-living space (Zostel) for his stays during his travels, confessed to his wariness: 'I've decided not to travel until it's safe to do so, which is until we have a cure or a vaccine.' Although he lauded the chain for their hygienic facilities, he would still expect them to up the ante and ensure extreme sanitization measures. When asked if he would 
use dormitories/bunker beds with strangers once he resumes travelling, he replied: 'If I'm traveling solo, I'd have no option as that's the most economical way to travel and I'd like to meet new people; but if I'm in a group, I'd try to get a group accommodation, separate from other people.'

These views were corroborated by another interviewee who runs a guest house and a dormitory in a popular tourist spot. The gentleman expressed his willingness to abide by the rules stipulated by the local government regarding physical distancing; he commented on his preparedness: 'I was in a meeting with the district collector regarding reopening guest houses for tourists. I have readied all the measures for guest safety, including temperature scanners, sanitisers, gloves and masks for staff, creating more space between beds and reducing number of beds, single accommodation in tents and so on, but I am still concerned about the possibility of the pandemic resurging once travel restrictions are lifted.' When asked about his revenue recovery, he opined: 'The three months of lock down have already cost us a significant loss; I am receiving a few enquiries, but it'll take at least 6-12 months for the revenues to return to normalcy. Besides, now that we have to follow distancing, I have to reduce the number of beds offered.' Would he transfer the extra overhead to his customers? 'No sir, when the times were good, we made good money from tourists; now it'd be unfair of us to burden them. I agree we have to now invest more for hygiene and distancing and that adds to our costs, but for the near future at least, I'll not hike the fares. But I'm not sure about the other home owners.'

Similar views were shared by Mr. Ritesh Agarwal in his interview: 'The COVID-19 pandemic has created fundamental shifts in consumer behaviour, especially related to travel and hospitality. Higher hygiene standards, minimal contact service and enhanced credibility top the list of consumer requirements while planning travel after the lockdown. We recently launched the Sanitised Stays initiative where we are training our partners to offer a minimal touch experience to consumers during check in/check out, room service and also visibility of the sanitisation level of a property on our online platforms. Our hotels will go through regular background audit checks for sanitisation, hygiene and protective equipment. We will be training 1,000 hotel partners over the next few days under this program.' (Anon., 2020). An Oyo user we interviewed said: 'If I have to live in an Oyo Life again, I'd rather have the entire room to myself. Even if it means I'd be paying more, at least I'd have the pantry and bathroom to myself.'

\section{Shared Mobility}

The researchers interviewed seven people from the following cities: Mumbai, Pune, Bengaluru. The interviewees were all working professionals who used shared transport for their office commutes such as carpooling, office transport and shared public transport (cabs, trains and autos). While many of the users were working from home at the time of the interviews, they expected to be back in office sooner than later, which merits a consideration towards the mode of transport they' $\mathrm{d}$ adopt in the COVID-19 scenario.

Plainly speaking, shared mobility could be defined as usage of shared vehicles to optimise occupancy, cost and efficiency. In this model, individuals move away from owning a vehicle and prefer to use/share one only when needed. The model includes public transport, taxi aggregators, bike taxis, carpooling and so on. The idea is broadly to minimise the wastage caused by private vehicles when they're unused. Benefits include reduced transportation cost, reduced fuel usage, reduced emissions and better connectivity. 
In 2018, Government of India's think tank NITI Aayog published a report titled 'Moving Forward Together'. The report underscored the proven benefits of shared mobility and also outlined the plans of the government to encourage adoption of the same. An excerpt from the report: 'Preliminary results show that by reducing transportation demand through transit-oriented development and improving asset utilization with high adoption of ridesharing and public transit, India can reduce annual mobility demand by nearly 1,800 billion vehicle $\mathrm{km}$ in $2035^{\prime}$ (NITI Aayog, 2018).

In its 2020 Global Automotive Consumer Study (January 2020), Deloitte published insights about Indians' opinions regarding shared mobility. To the following question: 'Does your use of ridehailing services make you question whether you need to own a vehicle going forward?' a whopping 61 per cent of respondents (average across all generations) answered affirmatively (Deloitte, 2020).

And then COVID-19 struck. People were forced to stay indoors and work from home wherever possible. In other cases, employees were furloughed or even laid off. For three months, most Indian workers shunned mass transit, as only essential workers were allowed to travel for work. Transportation providers naturally took a hit. In his 20 May 2020 note to employees, Ola cofounder, Bhavish Aggarwal, wrote: 'The fallout of the virus has been very tough for our industry in particular. Our revenue has come down 95\% over the past 2 months. Most importantly, this crisis has affected the livelihoods of millions of our drivers and their families across India and our international geographies'; 'In these circumstances, today I write to all of you with the toughest decision I have ever taken - the need to downsize our organization and let go of 1400 of our valued employees.' This was about a third of Ola's workforce. A week later, Uber India laid off 600 employees. Ola and Uber have also suspended their cab-sharing options.

These taxi aggregators have implemented measures in sync with social distancing and sanitisation norms, something that our interviewees are aware of: 'I avoid shared autos/cabs if there's no separation between driver and passenger and between passengers,' 'I make sure driver is wearing a mask, before starting the ride,' 'I expect compliance from both ends - customer and taxi aggregator.' About the natural increase in price hikes since the pandemic due to suspension of ride-sharing, the respondents said: 'I'm okay with increased charges,' 'I'd travel alone in Ola/Uber/auto even if it costs more.' A share-auto user said: 'I'm okay with price hike, but I expect the number of people to reduce from eight to four.' In case of bike taxis (like Rapido) and shared two-wheelers (like Bounce, Vogo, etc.), an interviewee said: 'I've given up using Rapido and Bounce since I wouldn't know who would've used the vehicles before me.'

When it comes to carpooling, with or without the aid of mobile apps, our users had to say this: 'I was carpooling earlier with my colleagues but am travelling alone on my bike now, due to rules and risk of transmission. You never know who can be a disease carrier.' 'I used to use Quickride to share rides to office. Now when I offer Quickride, I allow only one person with Safety badge (an initiative by Quickride that classifies people as safe from COVID-19); when I search for a ride I expect only two people to be in the vehicle; I'm keeping the charges same as before (pre-COVID19) when I offer a ride; when looking for a ride, if I find people charging more, I use my own transport.'

The researchers also interviewed users of company-provided transport. The responses received were as follows: 'I will use bus due to lack of other options, plus the buses are sanitised and distancing is maintained; office bus fares are not increased for now, since many people are working 
from home. I'm averse to carpooling due to strangers and hygiene issues'; 'There's no social distancing followed in our office cabs, but as long as there is free transport to and from office, we are okay with it. And since the cab provider is under contract, they cannot hike the prices. Some employees who are not okay with cabs opt to work from home.'

When asked to comment on the possibility of purchasing a private vehicle for office commute, the responses were: 'Not considering own transport since my work location keeps shifting,' 'Not buying own vehicle since I do not have a driver's licence,' 'I'd say no to own transport due to exorbitant fuel prices' and 'A cab/auto is way cheaper for me for my regular commutes.'

\section{Shared Working/Co-working}

For our study related to co-working, we interviewed five working professionals based in Bengaluru and Gurugram. Although all of them are working from home currently, they have worked in a coworking location earlier.

Co-working spaces are used in two formats: the first being when a firm rents out a sizeable portion of co-working space for a team or all of its staff (in case of small firms); the other being when a firm allows an employee to work from a co-working location instead of its premises - the person might either be a regular employee or a freelancer.

Let us look at some of the attributes that make co-working spaces a hit:

Seamless set-up and operations - Co-working spaces allow for a hassle-free set-up. Firms need not bother about amenities (electricity/water/internet), security, décor or maintenance. It allows firms to focus on their businesses, for a reasonable payment. Also, when firms expand into new geographies, co-working spaces offer a toehold to test the waters without sinking money into real estate.

Gig economy - This refers to freelance workers who work for firms on a temporary basis. More often than not, the work is remote and a co-working space offers an office environment for a nonoffice goer.

Networking - A major reason why individuals and start-ups prefer co-working spaces is networking. In start-up hubs like Bengaluru and Delhi-NCR, co-working spaces are hotbeds of innovation due to the sheer diversity of people who work and engage.

Environment - Co-working spaces offer cafeterias, open pantries, brightly lit environs, standing tables, green indoor spaces, fluid work environment, football tables, regular engagement activities and other such lively initiatives, which perks up the mood of workers - especially young workers. Regular office spaces are comparatively drab and are often regarded as boring.

Notwithstanding the 2019 Wework fiasco, co-working spaces were doing pretty well in the beginning of 2020. In an interview dated 8 January 2020, when asked about possible downsides to co-working, WeWork India Chief, Karan Virwani, answered: 'I only see upsides to co-working!' (HBR Ascend, 2020). A report in Economic Times quoted a property consultant who said there were more than 200 co-working players, operating more than 350 centres across India. And that in the next couple of years, the numbers were expected to double or even triple (Press Trust of India, 2020). Cutting a long story short, co-working spaces seemed to have a dream run. Until COVID-19 surfaced. 
As firms issued mandatory work-from-home notices to their employees, a sudden, palpable decline in the footfall of co-workers was observed. Firms, unwilling to pay for unused spaces, started to demand modifications in their lease agreements. In May 2020, Wework India laid off 20 per cent of its work force. The very idea of bringing people from varied commercial activities into a shared space is being seen as risky and unappetising by workers as a result of COVID-19.

One of our interviewees detailed her concerns thus: 'If my firm requires me to work from the coworking space, I'd avoid everyday visit and instead limit it to probably twice a week. I expect physical barriers between individual workstations, and sanitisers everywhere! Preferably, I'd work inside a cabin. If these are unobtainable, I'd at least expect physical distancing in the form of marks on the floor, in addition to contactless facilities in the pantries and washrooms. I'd really prefer to work from home right now.' Another user echoed her comments: 'We're sort of adjusted to working from home in these three months; I've also noticed increased productivity from my teammates. I can see why offices are exiting co-working spaces and betting on working from home.' There's also the pragmatic move of firms offering a fixed allowance to set up workstations at home, as one user observes: 'In case there's a breakout of COVID-19 in a co-working space, who's answerable? The onus is on employees to maintain distance, but that doesn't guarantee prevention. Instead of paying for the space here, offices should dole out the money to employees for setting up required facilities to work from home.' Another user thinks about companies establishing their own offices: 'If co-working spaces implement physical distancing strictly, it'd lead to reduction of capacity per floor. With reduced users, co-working spaces might step up the rents to make up for lost revenue. Small firms with tight budgets might very well think about getting a separate office space instead of paying extra over here.' One young user, however, stuck to his admiration for co-working spaces: 'I use co-working spaces for the connections I can make, which would be necessary for someone who is active in the start-up ecosystem. I'm ready to risk COVID-19 for this.'

\section{ANALYSIS AND INTERPRETATION}

We give below the analyses and interpretations derived from the research:

\section{Shared Living:}

1. Branded accommodation providers are facing heat; they've been forced to lay employees off as their businesses have been halted. People choose to return to their homes and work from home or attend online classes.

2. Four out of six of our interviewees lived in shared spaces either temporarily or for long durations. It is a general opinion of users who have lived with their co-occupants for a considerable duration before COVID-19 that they are comfortable sharing space with known faces. However, when they have to choose a new location, users prefer to either move in with a familiar person, or choose to keep an entire room for themselves.

3. They expect better hygiene to be implemented by the facility manager, including more frequent sanitisation of the pantry area, lifts and so on. Users are also exhibiting a self- 
induced ghetto like behaviour, where they have limited their venturing-out to essential needs only, and expect visitors to be restricted from entering their premises.

4. Another interesting observation is their decision to avoid unnecessary contact while gathering for meals in the common dining area, or availing the services of a maid/cook. Instead, they'd rather cook their food themselves. This decision was aided by the fact that all the respondents were working from home at the time of the interviews, which allowed them more time for domestic chores.

5. Cost is not an issue for users, in case of hikes due to reduced occupants in a living space.

6. Hospitality industry, which shares a close bond with travel and tourism industries, has practically been brought to a halt. The general attitude of both travellers and hosts seems to be caution. While some have resumed travelling and hosting, most others are wary and would rather lie low until the pandemic is over. The need to recover revenue lost in the preceding months, combined with an increase in operational costs, might lead hosts to drive up their boarding fees, which may further alienate them from budget conscious travellers.

\section{Shared Mobility:}

1. Major taxi aggregators in India have suffered huge blows since a majority of populace was restricted from travelling and regular commute.

2. And when it comes to using cabs and autos, users are either averse to sharing their ride or expect reduced passengers with strict physical distancing. They also expect the vehicle to be sanitised and the driver to follow safety protocols. Users are alright with spending extra over cabs and autos as long as it keeps them safe from contacting COVID-19.

3. Users are not very keen on own vehicles due to a gamut of reasons, including not having a license or high fuel prices or even because of constant movement across geographies. Although they are wary of the pandemic, they are still comfortable using shared vehicles.

4. Carpooling is not as popular as before, due to the obvious risk of contact with strangers and trust deficit with non-strangers. Another reason seems to be increased share of cost for each person pooling.

5. Company transport seems to be getting a good response, majorly because the fares haven't been hiked for the time being; however, it appears that not all companies are enforcing physical distancing or sanitisation.

\section{Shared Working:}

1. COVID-19 has dealt a major blow to co-working spaces. A majority of users opined that they would stay away from co-working spaces, while companies are vacating their rented spaces. Personal safety is taking precedence over networking, at least for the majority of users.

2. Working from home has picked up as the new trend, as firms are encouraging majority of their workforce to work remotely. Employees say that over months, they are adapting to the new lifestyle.

3. People who can't help using co-working spaces are naturally expecting safety measures to be in place - including sanitisation and physical distancing. However, they'd still prefer to avoid everyday usage. 
Karthik \& Sinha | The Impact of Physical Distancing on the Sharing Economy

4. Space providers are staring at a twin crisis - reduction in footfall and increase in operational overhead costs. Apart from hiking the usage fee, they don't have any other way to recover their expenses.

5. As smaller space providers are shutting shop and larger ones are cutting costs by way of layoffs, analysts are predicting a bleak outlook for co-working, at least for the near future, until we tide over the crisis.

\section{DISCUSSION AND RECOMMENDATIONS}

While trying to answer how COVID-19 has impacted the consumer behaviour in relation to sharing economy, we see that the consumers are now more mindful, even wary, while choosing shared facilities. When we consider shared accommodations, this pandemic might very well have been the death knell for dingy, shady residences, since users seem to prefer spacious, healthy places to reside. It's also an opportunity for future builders to factor in social distancing and better ventilation. Oyo, in a statement, detailed how it has opened up its accommodations during COVID19 for frontline healthcare workers. This is a positive way to score brownie points in the minds of future users, while also helping them get publicity. Although demand has fallen currently, residence owners could use this opportunity to redesign their offerings. For when students return to educational institutions, companies open up to accommodate more employees or travellers resume travelling, they would be on the lookout for health-compliant spaces.

When it comes to how the pandemic has affected the mindsets of people in the long and short run, the researchers have surmised that people are averse to return to normalcy any time soon. Travellers are hesitant to be in the presence of strangers. Passengers are averse to travelling with strangers. With people behaving thus, it'll be a long time before carpooling or shared taxis return to mainstream mobility. What's certainly possible in transportation is innovations in vehicle design, with physical distancing in mind. Taxi aggregators have implemented hygiene and distancing protocols, along with health-certifying their drivers, thereby instilling confidence in users.

Another cause of concern is that with public transport in shambles, the populace might choose to own their vehicles, which could in theory lead to more emissions and traffic conundrums. It would be wise for the government to anticipate this scenario and draw plans to keep cities congestionfree. In addition to following distancing and hygiene, some more initiatives for public transport could be contactless ticketing, health certificates for vehicle operators and dedicated bus lanes.

And hence it is imperative that interpersonal interactions have been affected in shared spaces: of the three kinds of sharing economies we've explored in this paper, shared working is the worst hit. COVID-19 is a human-borne disease. Lock downs and work-from-home mandates have practically smothered the hopes of co-working spaces. As long as there's a large concentration of people in one place for extended periods, there's always a threat of the disease spreading.

Owners of co-working spaces, as in the case of shared-living space providers, could use this down time to redo their spaces to ensure distancing. And to ensure safety, open work spaces would need to segregate the floors into smaller spaces or cabins with separate ventilation, ensure more cleaning and sanitization and minimise contact. 
In conclusion, COVID-19 has been an intriguing phenomenon. In a way, it has exposed chinks in the armour of businesses that were ignorant of the possibility of a pandemic ruining their victory run. While some businesses have been drastically affected, it is still not too late to make amends and get back in the game. As Leon C. Megginson, professor of Management and Marketing at Louisiana State University, observes: 'According to Darwin's Origin of Species, it is not the most intellectual of the species that survives; it is not the strongest that survives; but the species that survives is the one that is able best to adapt and adjust to the changing environment in which it finds itself.' We couldn't agree more.

\section{LIMITATIONS OF THE STUDY}

For this research, the authors have focused on the effect of physical distancing on sharing economy. Within sharing economy, we have paid attention only to shared living, shared transport and shared working - there are other possible shared spaces such as restaurants, malls, gymnasiums, educational institutions, places of worship and so on, which do not fall under the ambit of this paper.

While researching shared living, the researchers have not interviewed students living in shared PGs or hostels or dormitories. The reason for this is the fact that students are not primary decision makers when it comes to choosing and paying for their accommodations. More often than not, it is the institutions themselves or parents who take a call. This is not the case with salaried adults who have been interviewed. Additionally, we have not explored shared living in the context of people living with extended family or friends on a no-payment basis.

Sample selection: Almost all the persons interviewed for this research are residents of metropolises; the research does not address the impact of COVID-19 on sharing economies in nonurban areas.

Previous research on this topic: Since this research is about the effects of a contemporary pandemic, earlier, established research is unobtainable. When it comes to assessing the impact, we have not referred to contemporary research addressing the topic. This is a possible window that is open to further exploration.

Due to paucity of time, the researchers could not conduct a thorough, extended research into effect of COVID on individuals from a larger population. Only qualitative methods have been applied to collect data to ascertain general behavioural changes of consumers. However, this research could be expanded in future to include more data and gathered via other methodologies. 
Karthik \& Sinha | The Impact of Physical Distancing on the Sharing Economy

\section{REFERENCES}

(UNAIDS), J. U. N. P. o. H., 2002. Report on the global HIV/AIDS epidemic., Geneva: UNAIDS.

Andersen, K. \& Rambaut, A. e. a., 2020. The proximal origin of SARS-CoV-2. Nature, 17 March, pp. 450-452.doi:10.1038/s41591-020-0820-9.

Anon., 2020. Lachmi Deb Roy INTERVIEWS Ritesh Agarwal. Outlook, 6 June.

Asian Development Bank, 2020. Asian Development Outlook (ADO) 2020: What Drives Innovation in Asia?. s.1.:http://dx.doi.org/10.22617/FLS200119-3.

Cantore, N., Hartwich, F. \& al, e., 2020. Coronavirus: the economic impact, s.1.: Unido.org.

Cohn, S. K. J., 2007. The Black Death and the Burning of Jews. Oxford Academic Past \& PResent, p. 3-36.doi:10.1093/pastj/gtm005.

Deloitte, 2020. 2020 Global Automotive Consumer Study, s.1.: Deloitte.

Detrixhe, J., 2020. Nobel prize winning economist Robert Shiller says this economic disruption is different. Quartz, 13 March.

ECLAC, 2020. Inter-American Dialogue teleconference on the effects of the Coronavirus in Latin America and the Caribbean, s.1.: CEPAL.org.

Ferguson, N. \& Laydon, D. e. a., 2020. Report 9: Impact of non-pharmaceutical interventions (NPIs) to reduce COVID19 mortality and healthcare demand. http://hdl.handle.net/10044/1/77482, 16 March, pp. 1-20.doi:10.25561/77482.

Gayle, H. D. e. a., 2001. Global Impact of Human Immunodeficiency Virus and AIDS. Clinical Microbiology Reviews. 2001 Apr; 14(2), pp. 327-335.doi:10.1128/CMR.14.2.327335.2001 .

Hastings, P. R. S. e. a., 2016. Reviewing the History of Pandemic Influenza: Understanding Patterns of Emergence and Transmission. Pathogens, pp. 566.doi: 10.3390/pathogens5040066.

HBR ascend, 2020. The Rise of Coworking Spaces in India. 8 January.

Humphries, M. O., 2014. Paths of Infection: The First World War and the Origins of the 1918 Influenza Pandemic. Sage journals, Volume: 21 issue: 1, pp. 5581.doi:10.1177/0968344513504525.

IMF, 2020. World Economic Outlook 2020 Chapter-1 The great lockdown, s.1.: IMF.org. 
Jedwab, R. e. a., 2017. Negative Shocks and Mass Persecutions: Evidence from the Black Death. Institute for International Economic Policy Working Paper Series, pp. 146.doi:10.1007/s10887-019-09167-1.

Johnson, N. P. e. a., 2002. Updating the Accounts: Global Mortality of the 1918-1920 "Spanish" Influenza Pandemic. Bulletin of the History of Medicine 76.1 (2002) , pp. 105-115.

NITI Aayog, 2018. MOVING FORWARD TOGETHER, s.1.: NITI Aayog.

OECD, 2020. Secretary General Angel Gurria's Statement for the G20 Videoconference Summit on COVID-19, s.1.: OECD.org.

Prem, K. \& al, L. Y. e., 2020. The effect of control strategies to reduce social mixing on outcomes of the COVID-19 epidemic in Wuhan, China: a modelling study. Lancet Public Health, 25 March, pp. 1-10.doi:10.1016/S2468-2667(20)30073-6.

Press Trust of India, 2020. Number of coworking centres likely to double or treble in 2 yrs: Anarock. The Economic Times, 3 January.

Ren, L.-L., Wang, Y.-M. \& al, e., 2020. Identification of a novel coronavirus causing severe pneumonia in human: a descriptive study. Chinese medical journal. , p. doi:10.1097/CM9.0000000000000722.

Rosen, W., 2007. JUSTINIAN'S FLEA - PLAGUE, EMPIRE, AND THE BIRTH OF EUROPE. s.1.:Viking.

TNN, 2020. How China contained the Coronavirus after early blunders. The Economic Times, 13 March.

Waring, J. I., 1964. A History of Medicine in South Carolina: 1900-1970. Vol. 3. South Carolina Medical Association.

World Bank, 2020. Africa's pulse: ASSESSING THE ECONOMIC IMPACT OF COVID-19 AND POLICY RESPONSES IN SUB-SAHARAN AFRICA, s.l.: World Bank.

Zhou, P., Yang, X., Wang, X. \& al., e., 2020. A pneumonia outbreak associated with a new coronavirus of probable bat origin. Nature, pp. 270-273. doi:10.1038/s41586-020-20127. 